\title{
Fixação de nitrogênio e produção de ácido indolacético in vitro por bactérias diazotróficas endofíticas
}

\author{
Anelise Vicentini Kuss ${ }^{(1)}$, Vivian Vicentini Kuss ${ }^{(1)}$, Thomé Lovato ${ }^{(1)}$ e Maristela Lovato Flôres ${ }^{(1)}$
}

(1)Universidade Federal de Santa Maria, Centro de Ciências Rurais, Av. Roraima, s/no, prédio 42, CEP 97105-900, Santa Maria, RS. E-mail:anevk@mail.ufsm.br, vivian.eq@hotmail.com, thome.ufsm@gmail.com, maristelalf@smail.ufsm.br

\begin{abstract}
Resumo - O objetivo deste trabalho foi isolar e quantificar bactérias diazotróficas associadas a raízes de arroz, e avaliar a produção de ácido indolacético e o potencial de fixação biológica de nitrogênio dessas bactérias, a fim de selecionar isolados promissores para inoculação em plantas. Bactérias fixadoras de nitrogênio, habitantes do interior das raízes de cultivares de arroz do Rio Grande do Sul, foram isoladas e quantificadas em nove cultivares. Raízes de arroz superficialmente esterilizadas foram maceradas e introduzidas em meios de crescimento, elaborados sem fonte de nitrogênio e em condições semi-sólidas. Entre os 58 isolados nos meios NFb, LGI e LGI-P, foram escolhidos UFSM-BD-02-06, UFSM-BD-08-06, UFSM-BD-14-06, UFSM-BD-20-06, UFSM-BD-26-06, UFSM-BD-31-06, UFSM-BD-36-06, UFSM-BD-42-06, UFSM-BD-48-06, UFSM-BD-54-06. Avaliaram-se a fixação biológica de nitrogênio e a produção de ácido indolacético in vitro, pelos métodos Kjeldahl e colorimétrico, respectivamente. Azospirillum brasilense e A. lipoferum apresentam maiores valores para $\mathrm{N}$ total, 41,08 e 46,82 $\mathrm{g} \mathrm{mL}^{-1}$, respectivamente. A. brasilense e UFSM-BD-31-06 são os maiores produtores de ácido indolacético, $41,09 \mu \mathrm{g} \mathrm{mL}^{-1}$ e $13,47 \mu \mathrm{g} \mathrm{mL}^{-1}$, respectivamente.
\end{abstract}

Termos para indexação: auxinas, fixação biológica de nitrogênio, isolamento, raízes de arroz.

\section{Nitrogen fixation and in vitro production of indolacetic acid by endophytic diazotrophic bacteria}

\begin{abstract}
The aim of this work was to isolate and to quantify diazotrophic bacteria associated with rice root, and evaluate their acid indolacetic production and their potential for biological nitrogen fixation, with the purpose of selecion promissing isolates for plant inoculation. $\mathrm{N}$-fixing bactéria, settlers of the root interior of rice cultivars used in Rio Grande do Sul, Brazil, were isolated and quantified in nine cultivars. Rice root superficialy sterilized were macerated and introduced in specific culture media. Among 58 isolates obtained in the culture media NFB, LGI and LGI-P, the following were selected: UFSM-BD-02-06, UFSM-BD-08-06, UFSM-BD-14-06, UFSM-BD-20-06, UFSM-BD-26-06, UFSM-BD-31-06, UFSM-BD-36-06, UFSM-BD-42-06, UFSM-BD-48-06, UFSM-BD-54-06. The biological nitrogen fixation was determined by the Kjeldahl method, and indolacetic acid production by colorimetry. Azospirillum brasilense e A. lipoferum present greater values, 41.08 and $46.82 \mu \mathrm{g} \mathrm{N} \mathrm{mL}^{-1}$, respectively, for total $\mathrm{N}$, and for indolacetic acid production, A. brasilense, $41.09 \mu \mathrm{g} \mathrm{mL}{ }^{-1}$, and UFSM-BD-31-06, $13.47 \mu \mathrm{g} \mathrm{mL}^{-1}$, are the greatest producers.
\end{abstract}

Index terms: auxin, biological nitrogen fixation, isolation, rice root.

\section{Introdução}

Bactérias que habitam as raízes de plantas e exercem efeitos positivos sobre elas são denominadas rizobactérias promotoras de crescimento vegetal. Os efeitos positivos desses organismos podem ocorrer por influência direta (aumento da solubilização e entrada de nutrientes ou produção de reguladores de crescimento vegetal) ou indireta (supressão de patógenos, por produção de sideróforos ou antibióticos) (Asghar et al., 2002). Pela sua habilidade em converter nitrogênio atmosférico em amônia, que pode ser utilizada pela planta, as bactérias diazotróficas também são consideradas promotoras de crescimento vegetal. Em razão de sua capacidade de sobreviver em ambientes deficientes em nitrogênio, as bactérias diazotróficas podem enriquecer seletivamente a rizosfera, local em que habitam como organismos de vida livre ou estão associadas assimbioticamente a plantas (Dobbelaere et al., 2003).

Avanços significativos ocorreram nas pesquisas sobre FBN em gramíneas, com a descoberta do meio semisólido NFb (Oliveira et al., 2002). Elaborado sem fonte 
nitrogenada, a condição de semi-sólido cria um ambiente com baixo nível de oxigênio, semelhantemente ao que ocorre no solo ou na planta, onde estão localizadas bactérias diazotróficas microaerofílicas associadas a raízes de plantas. A formulação desse meio facilitou o isolamento de bactérias do gênero Azospirillum e, após essa descoberta, muitas outras espécies de bactérias diazotróficas foram isoladas no Brasil, pertencentes aos gêneros Gluconacetobacter, Herbaspirillum e Burkholderia. Essas bactérias têm sido detectadas em altos números - entre $10^{4}$ e $10^{7}$ células $\mathrm{g}^{-1}$ de peso fresco -, e muitos estudos têm sido conduzidos para avaliar o suprimento de $\mathrm{N}$ fornecido às plantas hospedeiras (Oliveira et al., 2002; Baldani \& Baldani, 2005).

No caso de Azospirillum, respostas positivas à inoculação têm sido observadas em plantas, inclusive quando cultivadas com altos níveis de nitrogênio, o que indica que as respostas da planta não ocorrem apenas em razão do $\mathrm{N}_{2}$ fixado, mas, também, da produção de outras substâncias (Dobbelaere et al., 2003). As auxinas estão entre as substâncias de crescimento vegetal produzidas por Azospirillum e outros gêneros, das quais o ácido indolacético (AIA) é a mais ativa e melhor caracterizada (Crozier et al., 1988). O ácido indolacético é conhecido por produzir tanto respostas rápidas (aumento da elongação celular) como lentas (divisão e diferenciação celular) (Dobbelaere et al., 2003).

Estudos têm demonstrado que microrganismos rizosféricos são capazes de sintetizar reguladores de crescimento vegetal in vitro (Arshad \& Frankenberger, 1998). Sarwar \& Kremer (1995) avaliaram 16 isolados da rizosfera de diferentes plantas e verificaram que os isolados associados à raiz das plantas eram mais eficientes na produção de auxinas do que os não associados às plantas.

O objetivo deste experimento foi isolar e quantificar bactérias diazotróficas, associadas a raízes de diferentes variedades de arroz irrigado, e avaliar a produção de ácido indolacético e o potencial de FBN destas bactérias, a fim de selecionar isolados promissores para posterior inoculação em plantas.

\section{Material e Métodos}

Para o isolamento de bactérias diazotróficas endofíticas, raízes de arroz são desinfectadas superficialmente, para eliminar os microrganismos do solo e da parte externa. Foram utilizadas raízes de arroz das variedades Qualitá, Avaxi, Tio Taka, Epagri-108, Epagri-109, BR-IRGA-410, BR-IRGA-417, BR-IRGA-419 e IRGA-420.

As cultivares foram semeadas em Planossolo Hidromórfico eutrófico arênico, em área de várzea sistematizada, do Dep. de Fitotecnia da Universidade Federal de Santa Maria (RS), em 23/10/2004, em sistema pré-germinado com densidade de $120 \mathrm{~kg}$ de sementes por hectare. Aos 30 dias após a semeadura, na fase de perfilhamento, foram aplicados $300 \mathrm{~kg} \mathrm{ha}^{-1}$ de adubo 2-20-30 e $45 \mathrm{~kg} \mathrm{ha}^{-1}$ de $\mathrm{N}$ em forma de uréia comercial. A segunda aplicação de $\mathrm{N}$ foi de $45 \mathrm{~kg} \mathrm{ha}^{-1}$, aos 55-60 dias após a semeadura, na fase de diferenciação do primórdio floral. Foram aplicados os inseticidas Diafuran e Carbofuran. Não foi aplicado fungicida. As plantas utilizadas para contagem e isolamento de bactérias diazotróficas foram coletadas no fim do ciclo de desenvolvimento da planta, pouco antes da colheita.

Para a desinfecção das raízes, utilizou-se o método descrito por Döbereiner et al. (1995), que consiste em lavar as raízes de arroz em água corrente, retirar $15 \mathrm{~g}$, secar e desinfectar superficialmente, com as seguintes etapas: imersão das raízes por 10 min em cloramina-T a $1 \%$, 10 min em água destilada estéril, 10 min em tampão fosfato e 10 min em água destilada estéril. Porções de $10 \mathrm{~g}$ de raízes desinfectadas foram trituradas com $90 \mathrm{~mL}$ de solução salina ( $\left.8,5 \mathrm{~g} \mathrm{~L}^{-1} \mathrm{de} \mathrm{NaCl}\right)$ e, então, realizaram-se diluições seriadas de $10^{-2}$ a $10^{-7}$, tendo-se transferido sucessivamente $10 \mathrm{~mL}$ da suspensão, de cada diluição, para frascos com $90 \mathrm{~mL}$ de solução salina. De cada uma das diluições, alíquotas de $100 \mu \mathrm{L}$ foram colocadas em triplicata, em frascos de vidro de $15 \mathrm{~mL}$, com $5 \mathrm{~mL}$ dos meios semisólidos livres de $\mathrm{N}$ : NFb, JNFb, JMV, LGI e LGI-P.

$\mathrm{O}$ meio $\mathrm{NFb}$ para Azospirillum brasilense $\mathrm{e}$ A. lipoferum apresenta a seguinte composição em $\mathrm{g} \mathrm{L}^{-1}$ : ácido málico, $5 ; \mathrm{K}_{2} \mathrm{HPO}_{4}, 0,5 ; \mathrm{MgSO}_{4} .7 \mathrm{H}_{2} \mathrm{O}, 0,2$; $\mathrm{NaCl}, 0,1 ; \mathrm{CaCl}_{2} \cdot 2 \mathrm{H}_{2} \mathrm{O}, 0,02 ; \mathrm{KOH}, 4,5 ;$ e em mL: solução de micronutrientes, 2 ; solução de azul de bromotimol $(0,5 \%$ em 0,2 KOH), 2; solução de FeEDTA (solução 1,64\%), 4; e solução vitaminas, 1; pH 6,5 (Döbereiner et al., 1995). $\mathrm{O}$ meio $\mathrm{JNFb}$, para Herbaspirillum spp., contém em $\mathrm{g} \mathrm{L}^{-1}$ : ácido málico, 5; $\mathrm{K}_{2} \mathrm{HPO}_{4}, 0,6 ; \mathrm{KH}_{2} \mathrm{PO}_{4}, 1,8$; $\mathrm{MgSO}_{4} .7 \mathrm{H}_{2} \mathrm{O}, 0,2 ; \mathrm{NaCl}, 0,1 ; \mathrm{CaCl}_{2} .2 \mathrm{H}_{2} \mathrm{O}, 0,02$; $\mathrm{KOH}, 4,5$; e em mL: solução de micronutrientes, 2; solução de azul de bromotimol (0,5\% em 0,2 KOH), 2; solução de FeEDTA (solução 1,64\%), 4; solução vitaminas, 1; e pH 5,8 (Döbereiner et al., 1995). 
A composição do meio JMV, para crescimento de Burkholderia spp., apresenta, em $\mathrm{g} \mathrm{L}^{-1}$ : manitol, 5; $\mathrm{K}_{2} \mathrm{HPO}_{4}, 0,6 ; \mathrm{KH}_{2} \mathrm{PO}_{4}, 1,8 ; \mathrm{MgSO}_{4} .7 \mathrm{H}_{2} \mathrm{O}, 0,2 ; \mathrm{NaCl}$, 0,$1 ; \mathrm{CaCl}_{2} \cdot 2 \mathrm{H}_{2} \mathrm{O}, 0,02$; e em mL: solução de micronutrientes, 2 ; solução de azul de bromotimol $(0,5 \%$ em 0,2 KOH), 2; solução de FeEDTA (solução 1,64\%), 4; solução vitaminas, 1; pH 4,2-4,5 (Baldani et al., 2000). $\mathrm{O}$ meio LGI, para $A$. amazonense, contém em $\mathrm{g} \mathrm{L}^{-1}$ : sacarose, 5; $\mathrm{K}_{2} \mathrm{HPO}_{4}, 0,2 ; \mathrm{KH}_{2} \mathrm{PO}_{4}, 0,6 ; \mathrm{MgSO}_{4} .7 \mathrm{H}_{2} \mathrm{O}, 0,2$; $\mathrm{CaCl}_{2} \cdot 2 \mathrm{H}_{2} \mathrm{O}, 0,02 ; \mathrm{Na}_{2} \mathrm{Mo}_{4} \cdot 2 \mathrm{H}_{2} \mathrm{O}, 0,002$; e em mL: solução de azul de bromotimol (0,5\% em 0,2 KOH), 5; solução de FeEDTA (solução 1,64\%), 4; solução vitaminas, 1; pH 6 (Döbereiner et al., 1995). O meio LGI-P, para Gluconacetobacter spp., contém em $\mathrm{g} \mathrm{L}^{-1}$ : sacarose, 100; $\mathrm{K}_{2} \mathrm{HPO}_{4}, 0,2 ; \mathrm{KH}_{2} \mathrm{PO}_{4}, 0,6$; $\mathrm{MgSO}_{4} \cdot 7 \mathrm{H}_{2} \mathrm{O}, 0,2 ; \mathrm{CaCl}_{2} \cdot 2 \mathrm{H}_{2} \mathrm{O}, 0,02 ; \mathrm{Na}_{2} \mathrm{Mo}_{4} \cdot 2 \mathrm{H}_{2} \mathrm{O}, 0,002$; e em mL: solução de azul de bromotimol $(0,5 \%$ em $0,2 \mathrm{KOH}$ ), 5; $\mathrm{FeCl}_{3} .6 \mathrm{H}_{2} \mathrm{O}, 0,01$; e pH 5,5 (Döbereiner et al., 1995).

As estirpes BR-11001 de A. brasilense e BR-11080 de A. lipoferum (Tarrand et al., 1978), BR-11175 de H. seropedicae e BR-11281 de Gluconacetobacter diazotrophicus (Baldani et al., 1986), BR-11140 de A. amazonense (Magalhães et al., 1983), cedidas pela Embrapa Agrobiologia, foram usadas como padrão de comparação entre os isolados. Os frascos foram incubados a $30^{\circ} \mathrm{C}$ por sete dias, e foram considerados positivos para contagem aqueles que apresentaram uma película aerotáxica típica, próxima da superfície do meio. A contagem da população de bactérias diazotróficas foi realizada pela técnica do número mais provável (NMP), com uso da tabela de McCrady para três repetições por diluição (Döbereiner et al., 1995). Após a quantificação das populações nas diferentes cultivares, foram selecionados dois isolados dos meios NFb, LGI e LGI-P, para cada cultivar usada, de acordo com as características morfológicas das colônias de cada meio específico.

A partir dos tubos de maior diluição que apresentaram película característica, novos tubos passaram por inoculação com meio semi-sólido específico, em três repetições. Após incubação a $30^{\circ} \mathrm{C}$ por cinco dias, nova repicagem foi realizada, e os frascos foram incubados por três dias. Um dos tubos de cada meio foi, então, usado para repicagem, em placas com meio sólido específico, acrescido de $20 \mathrm{mg} \mathrm{L}^{-1}$ de extrato de levedura. As placas foram incubadas por sete dias a $30^{\circ} \mathrm{C}$, e as colônias com características das espécies de interesse foram selecionadas e novamente repicadas para meio semi-sólido. Após quatro dias, as colônias foram repicadas para frascos inclinados, com $5 \mathrm{~mL}$ de meio Batata sólido e incubadas por mais três dias, quando foram acrescentados, a cada frasco, $15 \mathrm{~mL}$ de glicerol $50 \%$ (crioproteção e isolamento de oxigênio), tendo sido em seguida armazenadas em congelador a $-14^{\circ} \mathrm{C}$.

Os isolados identificados como UFSM-BD-02-06, UFSM-BD-08-06, UFSM-BD-14-06, UFSM-BD-20-06, UFSM-BD-26-06, UFSM-BD-31-06, UFSM-BD-36-06, UFSM-BD-42-06, UFSM-BD-48-06, UFSM-BD-54-06, obtidos em meio $\mathrm{NFb}$, e os padrões A. brasilense e A. lipoferum foram inoculados em frascos de vidro de $100 \mathrm{~mL}$, com $10 \mathrm{~mL}$ de meio DYGS, com a seguinte composição em g L-1: glucose, 2; peptona, 1,5; extrato de levedura, 2; $\mathrm{KH}_{2} \mathrm{PO}_{4}, 0,5 ; \mathrm{MgSO}_{4} .7 \mathrm{H}_{2} \mathrm{O}, 0,5$; ácido glutâmico, 1,5; completados com água destilada até 1.000 mL; pH 6,8 (Rodrigues Neto et al., 1986). Os frascos foram incubados por dois dias, até que o meio turvasse. Após esse período, os meios com células foram centrifugados, o sobrenadante foi vertido fora, e o precipitado de células foi dissolvido em $5 \mathrm{~mL}$ de solução salina $\left(8,5 \mathrm{~g} \mathrm{~L}^{-1}\right)$. Com uso do espectrofotômetro a $600 \mathrm{~nm}$, foi determinada a densidade ótica (DO) de cada isolado, tendo-se acrescentado solução salina até se obter $\mathrm{DO}=0,5$.

Para quantificar as auxinas produzidas em meio de cultura, alíquotas de $500 \mu \mathrm{L}$ de solução de cada um dos isolados bacterianos, ajustadas para DO 0,5, foram colocadas para crescimento em $20 \mathrm{~mL}$ de meio DYGS e incubadas por 72 horas a $30^{\circ} \mathrm{C}$. Após esse período, $15 \mathrm{~mL}$ de cada uma das culturas homogeneizadas foram transferidas para tubos e centrifugadas a $10.016 \mathrm{~g}$ por, $15 \mathrm{~min}$, a $4^{\circ} \mathrm{C}$. Do sobrenadante obtido, $3 \mathrm{~mL}$ foram vertidos em frascos, aos quais foram adicionados $2 \mathrm{~mL}$ de reagente de Salkowski (Sarwar \& Kremer, 1995). Os frascos com o sobrenadante e o reagente de Salkowski foram, então, reservados por $30 \mathrm{~min}$ em ambiente escuro, para desenvolvimento de cor, que se apresenta rósea mais intensa quando há maior quantidade de ácido indolacético. A intensidade da cor foi determinada em espectrofotômetro a $535 \mathrm{~nm}$ (Asghar et al., 2002). A concentração dos compostos indólicos foi estimada com uma curva-padrão, previamente preparada com meio de cultura esterilizado não inoculado, e quantidades conhecidas de ácido indolacético de 0 , 25, 50, 100, 150, 200 e $300 \mu \mathrm{g} \mathrm{mL}^{-1}$ de acordo com a equação y $=0,0514 \mathrm{x}-0,0546\left(\mathrm{R}^{2}=0,9706\right)$.

Para a avaliação da FBN, $600 \mu \mathrm{L}$ de uma solução de bactérias previamente ajustada para DO de 0,5 , em 
espectrofotômetro a $600 \mathrm{~nm}$ (aproximadamente $10^{8} \mathrm{UFC} \mathrm{mL}^{-1}$ ), foram colocados em frascos com $10 \mathrm{~mL}$ de meio $\mathrm{NFb}$ semi-sólido, em triplicatas, incubados a $30^{\circ} \mathrm{C}$ por cinco dias. Após o crescimento bacteriano, foram armazenados em congelador a $-14^{\circ} \mathrm{C}$ até que fossem analisados. Procedeu-se à ruptura das células, para liberação do conteúdo celular, tendo-se retirado os tubos do congelador e os aquecido em microondas por 1 min por frasco. Da solução resultante (meio + conteúdo celular) foram vertidos $9,5 \mathrm{~mL}$ em tubos, para digestão pelo método semi-micro Kjeldhal (Tedesco et al., 1995).

Para digestão, adicionaram-se a cada tubo com as células lisadas $0,7 \mathrm{~g}$ de mistura de digestão (100 $\mathrm{g}$ de $\mathrm{Na}_{2} \mathrm{SO}_{4}+10 \mathrm{~g}$ de $\mathrm{CuSO}_{4} .5 \mathrm{H}_{2} \mathrm{O}+1 \mathrm{~g}$ de selênio em pó), $1 \mathrm{~mL}$ de $\mathrm{H}_{2} \mathrm{O}_{2}$ e $2 \mathrm{~mL}_{\text {de }} \mathrm{H}_{2} \mathrm{SO}_{4}$, nesta ordem. Os tubos foram aquecidos em bloco digestor por 2 horas, a $180^{\circ} \mathrm{C}$, e a temperatura foi elevada para $360^{\circ} \mathrm{C}$, mantida até que a mistura apresentasse a cor verde-palha. Ao atingir a cor, aguardou-se que a temperatura da mistura se reduzisse a aproximadamente $40^{\circ} \mathrm{C}$, para completar o volume com água destilada para $10 \mathrm{~mL}$. Como controle, utilizou-se meio de cultura sem inoculação. Procedeuse à destilação com $\mathrm{NaOH}$ e à titulação das soluções, para quantificação do $\mathrm{N}$ total $\left(\mathrm{N}_{\mathrm{t}}\right)$ (Tedesco et al., 1995). $\mathrm{O}$ cálculo de $\mathrm{N}_{\mathrm{t}}$ fixado foi apresentado em microgramas por militro de meio.

Os dados experimentais obtidos foram submetidos à análise de variância, e a comparação de médias pelo teste de Tukey, a 5\% de probabilidade, com uso dos procedimentos disponíveis no Sisvar (Ferreira, 2000).

\section{Resultados e Discussão}

Entre a população de bactérias presentes no interior das raízes das cultivares de arroz (Tabela 1) ocorreram grandes populações de bactérias diazotróficas endofíticas. Entre os isolados no meio NFb, as populações de bactérias relacionadas à Azospirillum brasilense e A. lipoferum diferiram numericamente entre si, apenas nas cultivares Qualitá e Avaxi, as quais apresentaram valores estatisticamente inferiores às outras cultivares.

No meio LGI, as populações de A. amazonense foram maiores na cultivar IRGA-420, porém, não diferiram estatisticamente das encontradas na BR-IRGA-410, que por sua vez não diferiram das população encontradas na cultivar Tio Taka. Essas mesmas foram, também, maiores que as das demais cultivares (Tabela 1). Observação semelhante foi descrita por Brasil et al. (2005), ao verificar que maiores populações de $A$. amazonense estavam presentes em braquiária e capim-carona, enquanto A. brasilense foi localizada em maior número em capim-mimoso.

Em meio JNFb, em que crescem bactérias do gênero Herbaspirillum, maiores populações foram encontradas nas cultivares IRGA-420, Epagri-109 e BR-IRGA-410, embora não tenham sido diferentes das demais cultivares, exceto para Qualitá e Avaxi. Em meio JMV (Burkholderia), a cultivar IRGA-420 apresentou maior população. Na cultivar Avaxi, observaram-se as menores populações para bactérias crescidas em meio $\mathrm{NFb}$ (Azospirillum brasilense e A. lipoferum), JNFb (Herbaspirillum) e LGI-P (Gluconacetobacter), porém em meio JMV (Burkholderia), não foram detectadas bactérias.

A diferença significativa verificada entre as diferentes cultivares pode estar relacionada a fotoassimilados, que fornecem fontes de carbono específicas e favorecem sua permanência no interior das raízes, ou a exsudatos radiculares que podem atrair os microrganismos para a região rizosférica (Valé et al., 2005). Bacilio-Jiménez et al. (2003) conduziram estudos de caracterização de

Tabela 1. Número de bactérias diazotróficas endofíticas $\left(\log _{10}\right)$ e respectivo porcentual, associados às raízes das cultivares de arroz irrigado (média de três repetições) ${ }^{(1)}$.

\begin{tabular}{|c|c|c|c|c|c|}
\hline Cultivar & $\mathrm{NFb}$ & $\mathrm{JNFb}$ & JMV & LGI & LGI-P \\
\hline Qualitá & $6,42 b(38,69)$ & $4,69 \mathrm{~d}(0,50)$ & ND (0) & $6,40 \mathrm{~cd}(44,22)$ & $6,44 \mathrm{ab}(15,58)$ \\
\hline Avaxi & $4,56 \mathrm{c}(1,18)$ & $3,81 \mathrm{~d}(0,25)$ & ND (0) & $6,42 \mathrm{~cd}(92,00)$ & $5,34 b(6,57)$ \\
\hline Epagri-109 & $7,86 \mathrm{a}(32,86)$ & $7,74 \mathrm{ab}(32,86)$ & $6,55 \mathrm{~b}(0,71)$ & $6,56 \mathrm{~cd}(0,71)$ & $7,86 \mathrm{a}(32,86)$ \\
\hline IRGA-420 & $7,86 \mathrm{a}(20,89)$ & $7,95 \mathrm{a}(20,90)$ & $7,86 \mathrm{a}(20,89)$ & $7,95 \mathrm{a}(20,90)$ & $7,86 \mathrm{a}(16,42)$ \\
\hline BR-IRGA-410 & $7,49 \mathrm{a}(19,50)$ & $7,42 \mathrm{abc}(15,32)$ & $6,45 b(2,09)$ & $7,40 \mathrm{ab}(62,67)$ & $5,34 \mathrm{~b}(0,42)$ \\
\hline BR-IRGA-419 & $8,11 \mathrm{a}(93,74)$ & $6,35 b c(2,68)$ & $5,33 \mathrm{~cd}(0,23)$ & $6,56 \mathrm{~cd}(2,01)$ & $6,45 \mathrm{ab}(1,34)$ \\
\hline Tio Taka & $7,40 \mathrm{a}(64,31)$ & $6,26 \mathrm{c}(9,65)$ & $6,32 \mathrm{bc}(2,36)$ & $7,12 b(23,58)$ & $6,64 \mathrm{ab}(0,10)$ \\
\hline BR-IRGA-417 & $6,34 \mathrm{a}(28,50)$ & $6,17 \mathrm{c}(29,79)$ & $5,24 \mathrm{~d}(2,85)$ & $6,45 \mathrm{~cd}(35,86)$ & ND (0) \\
\hline Epagri-108 & $8,11 \mathrm{a}(88,53)$ & $6,40 \mathrm{bc}(6,04)$ & $4,07 \mathrm{e}(0,92)$ & $6,37 \mathrm{~d}(3,22)$ & $6,46 \mathrm{ab}(1,29)$ \\
\hline CV $(\%)$ & 4,71 & 8,01 & 7,59 & 3,75 & 11,10 \\
\hline
\end{tabular}

${ }^{(1)}$ Médias seguidas por letras iguais, na coluna, não diferem entre si pelo teste de Tukey, a 5\% de probabilidade. 
exsudados radiculares em arroz e verificaram que bactérias endofíticas respondem à composição e concentração de aminoácidos presentes. Na cultivar Epagri-109, foi também localizada a maior população de bactérias endofíticas com uso do meio LGI-P, mas neste meio não foram detectadas bactérias em BR-IRGA-417.

As diferenças verificadas nas populações das diferentes cultivares foram semelhantes às verificadas por Knauth et al. (2005), que observaram diferenças consideráveis entre as comunidades de bactérias diazotróficas associadas às raízes de cultivares de arroz e na expressão do gene responsável pela enzima chave da fixação biológica de nitrogênio, a nitrogenase.

Quanto à porcentagem de isolados obtidos, observouse que grupos específicos de bactérias diazotróficas revelaram afinidade por diferentes cultivares. Isolados em meio $\mathrm{NFb}$ representam valores porcentuais próximos de $90 \%$ do total das bactérias diazotróficas presentes em BR-IRGA-419 e Epagri-108, de 20 a $65 \%$ em 'Qualitá', Epagri-109, IRGA-420, BR-IRGA-410, 'Tio Taka' e BR-IRGA-417, e apenas 1\% em 'Avaxi'.

No meio JNFb, verificou-se que até $10 \%$ do total de bactérias diazotróficas isoladas eram provenientes das cultivares de arroz Qualitá, Avaxi, IRGA-419, Tio Taka e Epagri-108, e de 15 a 30\% das bactérias provinham das variedades Epagri-109, IRGA-420, BR-IRGA-410 e IRGA-417. O meio JMV apresentou maior população proveniente de IRGA-420 (20,89\%), que ficou abaixo de $3 \%$ de representação para todas as outras cultivares avaliadas.

O meio LGI destacou-se em porcentual de diazotróficas isoladas da raiz de 'Avaxi' (92\%) e BR-IRGA-410 (63\%) e, neste meio, 20 a $45 \%$ das diazotróficas isoladas vieram das cultivares Qualitá, IRGA-420, Tio Taka e IRGA-417. Nas demais cultivares, foram encontrados menos de $3,5 \%$ do total das bactérias diazotróficas isoladas com uso meio LGI. No meio LGI-P, 15 a $33 \%$ de diazotróficas foram isoladas das cultivares Qualitá, Epagri-109 e IRGA-420, e nas outras cultivares, verificaram-se valores abaixo de $7 \%$.

Zamudio \& Bastarrachea (1994) inocularam uma mistura de espécies bacterianas em Triticum aestivum L. e observaram aderência preferencial de Azospirillum spp. às raízes, embora tenham verificado que todas as espécies foram eficientes ao ser aplicadas sob forma de inoculante com apenas uma das espécies bacterianas. Nehl et al. (1996) consideram que a qualidade dos exsudatos radiculares é a responsável pela preferência das bactérias pela cultivar e espécie vegetal a ser colonizada.

A habilidade de sintetizar fitormônios é amplamente distribuída entre bactérias associadas com plantas. Entre eles, a produção de ácido indolacético (AIA), que estimula tanto a elongação celular quanto a divisão e diferenciação celular nas plantas (Dobbelaere et al., 2003). As bactérias produzem AIA por várias vias de síntese. Triptofano é um precursor de AIA, pois sua adição em meios de cultura promove aumento da síntese, mas há vias independentes de triptofano. Bactérias diazotróficas do gênero Azospirillum são estudadas em razão de sua interação com gramíneas e por sintetizarem AIA por diferentes vias. No entanto, alguns autores sugerem que $90 \%$ do ácido indolacético sintetizado por este gênero é derivado de uma via independente da adição de triptofano ao meio de cultura, pois outros compostos podem ser metabolizados (Zakharova et al., 1999). Halda-Alija (2003), em seus experimentos, também verificou que houve produção de AIA pelos isolados de diazotróficas, mesmo quando não houve adição de triptofano ao meio de cultura. Em razão disso, o meio de cultivo para quantificação de auxinas, no presente experimento, não recebeu adição de triptofano. O extrato de levedura, componente do meio DYGS usado neste experimento, é fonte rica de aminoácidos, inclusive triptofano (Yamada et al., 2003).

Verificou-se que todos os isolados produziram AIA em meio de cultura (Tabela 2), que variou entre 2,79 e

Tabela 2. Produção de ácido indolacético (AIA) e valores de nitrogênio total, obtidos em meio de cultura com inoculação de bactérias diazotróficas endofíticas, isoladas de cultivares de arroz irrigado, após 72 horas de crescimento ${ }^{(1)}$.

\begin{tabular}{lccc}
\hline Cultivar de origem & Isolado & $\begin{array}{c}\mathrm{AIA}^{-1} \\
\left(\mu \mathrm{g} \mathrm{mL}^{-1}\right)\end{array}$ & $\begin{array}{c}\mathrm{N} \mathrm{total}^{1} \\
\left(\mu \mathrm{g} \mathrm{mL}^{-1}\right)\end{array}$ \\
\hline \multicolumn{1}{c}{-} & A. lipoferum $^{(2)}$ & $4,63 \mathrm{~cd}$ & $46,82 \mathrm{a}$ \\
Qualitá & $\begin{array}{c}\text { A. } \text { brasilense }^{(2)} \\
\text { UFSM-BD-02-06 }\end{array}$ & $2,79 \mathrm{c}$ & $41,09 \mathrm{a}$ \\
Avaxi & UFSM-BD-08-06 & $2,99 \mathrm{~d}$ & $12,99 \mathrm{~b}$ \\
Tio Taka & UFSM-BD-14-06 & $3,31 \mathrm{~cd}$ & $7,17 \mathrm{~b}$ \\
Epagri-109 & UFSM-BD-20-06 & $5,25 \mathrm{c}$ & $12,12 \mathrm{~b}$ \\
IRGA-420 & UFSM-BD-26-06 & $3,82 \mathrm{~cd}$ & $12,11 \mathrm{~b}$ \\
BR-IRGA-410 & UFSM-BD-31-06 & $13,47 \mathrm{a}$ & $11,62 \mathrm{~b}$ \\
BR-IRGA-419 & UFSM-BD-36-06 & $3,57 \mathrm{~cd}$ & $7,53 \mathrm{~b}$ \\
Tio Taka & UFSM-BD-42-06 & $7,94 \mathrm{~b}$ & $5,56 \mathrm{~b}$ \\
BR-IRGA-417 & UFSM-BD-48-06 & $3,83 \mathrm{~cd}$ & $8,63 \mathrm{~b}$ \\
Epagri-108 & UFSM-BD-54-06 & $4,34 \mathrm{~cd}$ & $9,35 \mathrm{~b}$ \\
\hline CV (\%) & - & 13,63 & 28,78 \\
\hline
\end{tabular}

${ }^{(1)}$ Médias seguidas por letras iguais, na coluna, não diferem entre si pelo teste de Tukey, a 5\% de probabilidade. ${ }^{(2)}$ Espécies pertencentes à Coleção de Culturas da Embrapa Agrobiologia, Seropédica, RJ. 
$13,47 \mu \mathrm{g} \mathrm{mL} L^{-1}$, quando quantificado em meio de cultura. Destacou-se o isolado UFSM-BD-31-06, obtido de raiz da cultivar BR-IRGA-410, com o mais alto valor, inclusive em relação aos padrões utilizados de A. lipoferum e A. brasilense. O menor valor foi verificado no isolado UFSM-BD-02-06, proveniente de arroz cultivar Avaxi. Valores semelhantes foram reportados por Crozier et al. (1988), que estudaram a produção de AIA por isolados de A. brasilense, provenientes de Zea mays L., e obtiveram valores entre $1,4 \mathrm{e} 26,1 \mu \mathrm{g} \mathrm{mL}^{-1}$, em culturas incubadas por 24 horas a $32^{\circ} \mathrm{C}$. Mascarua-Esparza et al., (1988) obtiveram valores de 36,5 a $77 \mu \mathrm{g} \mathrm{mL}^{-1}$, para A. brasilense, e 6,5 a $17,5 \mu \mathrm{g} \mathrm{mL}^{-1}$ para A. lipoferum, ambas as espécies isoladas de raízes de cactáceas crescidas em condições áridas.

Bactérias do gênero Azospirillum spp. são capazes de converter $\mathrm{N}$ atmosférico em amônia, sob condições microaerófilas e com baixos níveis de $\mathrm{N}$, pela ação do complexo nitrogenase (Steenhoudt et al., 2000).

Os valores de $\mathrm{N}$ total foram usados para avaliar o potencial de fixação biológica de $\mathrm{N}_{2}$ pelas bactérias (Fernandes et al., 2001), pois foram incubadas em meio de cultura sem fonte nitrogenada e, portanto, o $\mathrm{N}$ medido nessas culturas provém de sua fixação do ar. A condição microaerófila é condicionada pelo uso de meio semisólido para incubação dos isolados. Os valores de $\mathrm{N}$ total (Tabela 2), em meio de cultura, apresentaram grande faixa de variação, de 5,56 a 46,82 $\mu \mathrm{g} \mathrm{mL}^{-1}$. As bactérias A. lipoferum e A. brasilense apresentaram-se como os melhores fixadores de nitrogênio, com valores significativamente maiores em relação aos outros isolados. Han \& New (1998) testaram 258 isolados de Azospirillum quanto à FBN, pela técnica de redução de acetileno, e obtiveram, como neste experimento, isolados com altos, médios e baixos valores de fixação, de 0 a $154,9 \mathrm{nmol} \mathrm{C}_{2} \mathrm{H}_{4} \mathrm{mg}$ proteína ${ }^{-1} \mathrm{~h}^{-1}$.

Knauth et al. (2005) também detectaram muitas diferenças quanto à fixação de $\mathrm{N}_{2}$, entre cultivares de arroz, ao avaliar a expressão da enzima chave da FBN, a nitrogenase. Isto pode explicar as variações verificadas, já que os isolados foram obtidos de diversas cultivares de arroz. No entanto, a alta FBN in vitro pode não ocorrer no caso de inoculação das bactérias em sementes. Mantelin \& Touraine (2004) consideram que a fixação ativa de $\mathrm{N}_{2}$, pelas bactérias, não implica em transferência do $\mathrm{N}$ fixado para a planta, e Han \& New (1998) verificaram, em seus experimentos, que a FBN em meio de cultura não se relacionou com alta fixação de $\mathrm{N}_{2}$ em campo.

\section{Conclusões}

1. A cultivar de arroz irrigado IRGA-420 apresenta populações de bactérias diazotróficas maiores nos meios $\mathrm{NFb}, \mathrm{JNFb}, \mathrm{JMV}$, LGI e LGI-P e potencial para fixação biológica de nitrogênio.

2. Azospirillum lipoferum e A. brasilense apresentam baixa produção de ácido indolacético (AIA) in vitro, em relação aos demais isolados.

3. Quanto à produção de AIA, UFSM-BD-31-06 destaca-se como maior produtor, em relação aos outros isolados.

\section{Agradecimentos}

À Capes e à Fapergs, pela concessão de bolsa.

\section{Referências}

ARSHAD, M.; FRANKENBERGER, W.T. Plant growth-regulating substances in the rhizosphere: microbial production and functions. Advances in Agronomy, v.62, p.45-151, 1998.

ASGHAR, H.N.; ZAHIR, Z.A.; ARSHAD, M.; KHALIQ, A. Relationship between in vitro production of auxins by rhizobacteria and their growth-promoting activities in Brassica juncea L. Biology and Fertility of Soils, v.35, p.231-237, 2002.

BACILIO-JIMÉNEZ, M.; AGUILAR-FLORES, S.; VENTURAZAPATA, E.; PÉREZ-CAMPOS, E.; BOUQUELET, S.; ZENTENO, E. Chemical characterizations of root exudates from rice (Oriza sativa) and their effects on the chemotatic response of endophytic bacteria. Plant and Soil, v.249, p.271-277, 2003.

BALDANI, J.I.; BALDANI, V.L.D. History on the biological nitrogen fixation research in graminaceous plants: special emphasis on the Brazilian experience. Anais da Academia Brasileira de Ciências, v.77, p.549-579, 2005.

BALDANI, J.I.; BALDANI, V.L.D.; SELDIN, L.; DÖBEREINER, J. Characterization of Herbaspirillum seropedicae ge. nov., sp. nov., a root-associated nitrogen-fixing bacterium. International Journal of Systematic Bacteriology, v.36, p.86-93, 1986.

BALDANI, V.L.D.; BALDANI, J.I.; DÖBEREINER, J. Inoculation of rice plants with the endophytic diazotrophs Herbaspirillum seropedicae and Burkholderia spp. Biology and Fertility of Soils, v.30, p.485-491, 2000.

BRASIL, M.S.; BALDANI, J.I.; BALDANI, V.L.D. Ocorrência e diversidade de bactérias diazotróficas associadas a gramíneas forrageiras do Pantanal sul-matogrossense. Revista Brasileira de Ciência do Solo, v.29, p.179-190, 2005.

CROZIER, A.; ARRUDA, P.; JASMIM, J.M.; MONTEIRO, A.M.; SANDBERG, G. Analysis of indole-3-acetic acid and related indoles in culture media from Azospirillum lipoferum and Azospirillum brasilense. Applied and Environmental Microbiology, v.54, p.2833-2837, 1988. 
DOBBELAERE, S.; VANDERLEYDEN, J.; OKON, Y. Plant growth-promoting effects of diazotrophs in the rhizosphere. Critical Reviews in Plant Sciences, v.22, p.107-149, 2003.

DÖBEREINER, J.; BALDANI, V.L.D.; BALDANI, J.I. Como isolar e identificar bactérias diazotróficas de plantas nãoleguminosas. Brasília: Embrapa-SPI, 1995. 60p.

FERNANDES, M.F.; FERNANDES, R.P.M.; RODRIGUES, L.S. Bactérias diazotróficas associadas a coqueiros na região da baixada litorânea em Sergipe. Pesquisa Agropecuária Brasileira, v.36, p.1509-1517, 2001

FERREIRA, D.F. Manual do sistema SISVAR para análises estatísticas. Lavras: Universidade Federal de Lavras, 2000. 66p.

HALDA-ALIJA, L. Identification of indole-3-acetic acid producing freshwater wetland rhizosfere bacteria associated with Juncus effusus L. Cambridge Journal of Microbiology, v.49, p.781-787, 2003.

HAN, S.O.; NEW, P.B. Variation in nitrogen fixing ability among natural isolates of Azospirillum. Microbial Ecology, v.36, p.193201, 1998 .

KNAUTH, S.; HUREK, T.; BRAR, D.; REINHOLD-HUREK, B. Influence of different Oryza cultivars on expression of nifH gene pools in roots of rice. Environmental Microbiology, v.7, p.17251733, 2005

MAGALHÃES, F.M.; BALDANI, J.I.; SOUTO, S.M.; KUYKENDALL, J.R.; DÖBEREINER, J. A new acid-tolerant Azospirillum species. Anais da Academia Brasileira de Ciências, n.55, p.417-430, 1983.

MANTELIN, S.; TOURAINE, B. Plant growth-promoting bacteria and nitrate availability: impacts on root development and nitrate uptake. Journal of Experimental Botany, v.55, p.27-34, 2004.

MASCARUA-ESPARZA, M.A.; VILLA-GONZALEZ, R.; CABALLERO-MELADO, J. Acetylene reduction and indolacetic acid production by Azospirillum isolates from cactaceous plants. Plant and Soil, v.106, p.91-95, 1988.

NEHL, D.B.; ALLEM, S.J.; BROWN, J.F. Deleterious rhizosfere bacteria: an integrating perspective. Applied Soil Ecology, v.5, p.120, 1996.

OLIVEIRA, A.L.M.; URQUIAGA, S.; DÖBEREINER, J.; BALDANI, J.I. The effect of inoculating endophytic $\mathrm{N}_{2}$-fixing bacteria on micropropagated sugarcane plants. Plant and Soil, v.242, p.205215,2002

RODRIGUES NETO, J.; MALAVOLTA JÚNIOR, V.A.; VICTOR, O. Meio simples para isolamento e cultivo de Xantomonas campestris pv. citri tipo B. Summa Phytopathologica, v.12, p.16, 1986.

SARWAR, M.; KREMER, R.J. Enhanced suppression of plant growth through production of L-tryptophan-derived compounds by deleterious rhizobacteria. Plant and Soil, v.172, p.261-269, 1995.

STEENHOUDT, O.; VANDERLEYDEN, J. Azospirillum, a freeliving nitrogen-fixing bacterium closely associated with grasses: genetic, biochemical and ecological aspects. FEMS Microbiology Reviews, v.24, p.487-506, 2000.

TARRAND, J.J.; KRIEG, N.R.; DÖBEREINER, J. A taxonomic study of the Spirillum lipoferum group, with descriptions of a new genus, Azospirillum gen. nov. and two species, Azospirillum lipoferum (Beijerinck) comb. nov. and Azospirillum brasilense sp. nov. Canadian Journal of Microbiology, v.24, p.967-980, 1978.

TEDESCO, M.J.; GIANELLO, C.; BISSANI, C.A.; BOHNEN, H.; VOLKWEISS, S.J. Análises de solo, plantas e outros materiais. Porto Alegre: Universidade Federal do Rio Grande do Sul, 1995. 174p. (Boletim Técnico de Solos, 5).

VALÉ, M.; NGUYEN, C.; DAMBRINE, E.; DUPOUEY, J.L. Microbial activity in the rhizosphere soil of six herbaceous species cultivated in a greenhouse is correlated with shoot biomass and root C concentrations. Soil Biology and Biochemistry, v.37, p.23292333, 2005.

YAMADA, E.A.; ALVIM, I.D.; SANTUCCI, M.C.C.; SGARBIERI, V.C. Composição centesimal e valor protéico de levedura residual da fermentação etanólica e de seus derivados. Revista de Nutrição, v.16, p.423-432, 2003.

ZAKHAROVA, E.A.; SHCHERBAKOV, A.A.; BRUDNIK, V.V.; SKRIPKO, N.G.; BULKHIN, N.S.; IGNATOV, V.V. Biosynthesis of indole-3-acetic acid in Azospirillum brasilense: insights from quantum chemistry. European Journal of Biochemistry, v.259, p.572-576, 1999.

ZAMUDIO, M.; BASTARRACHEA, F. Adhesiveness and root hair deformation capacity of Azospirillum strains for wheat seedlings. Soil Biology and Biochemistry, v.26, p.791-797, 1994. 